\title{
Designing the future cities: trends and issues from the interaction design perspective
}

\author{
Simone Pozzi ${ }^{1 *}$ and Sebastiano Bagnara ${ }^{2}$
}

\begin{abstract}
Background: The design of future cities is a challenging endeavour, to which interaction design can contribute by applying its well-established principles and methods. Interaction design methods aim at optimising interactions between humans, tools and environments, considering material tools, immaterial aspects like the interaction modalities, contextual aspects.

Methods: This contribution is structured like a literature review, discussing the applicability of design methods into urban settings. The first part reviews the key features and scope of three different design methods (nudges, persuasive technologies, and design thinking) and proposes a categorisation of city layers to identify possible intervention focuses.

Results: The following of this contribution discusses one major issue that an interaction design approach may encounter while intervening in a city, i.e. how to structure a user-centred process when users are in the order of a multitude, hence hard to be segmented.
\end{abstract}

Conclusions: In the last section, the concept of breakdown, derived from the human-computer interaction literature, is proposed as a way to partially overcome this issue.

\section{Introduction}

Interaction design is the discipline that makes use of digital technologies to design and put into place new services, to create value, and improve human wellbeing, with the aim to make possible what was not before, removing physical and social constraints to participation and active life (Rogers et al. 2007). This discipline may become particularly intriguing when technologies and services are to be designed for urban settings.

Cities are complex and they may shape the immediate context of the design intervention in unexpected ways. This contribution aims to put forward opportunities and issues an interaction design perspective is likely to encounter when intervening in a city context.

The contribution is organized in three parts: 1) A review of the three different design approaches that have gained more and more popularity in the last years: policy-making and nudges, persuasive technologies, and design thinking. 2) In order to clarifying which part of a

\footnotetext{
*Correspondence: simone.pozzi@gmail.com

${ }^{1}$ University of San Marino-IUAV, San Marino Città, San Marino \& Deep Blue Consulting and Research, Rome, Italy

Full list of author information is available at the end of the article
}

city could be targeted by an interaction design intervention, it is proposed to distinguish a number of different city layers, each one having its own time and space dynamics. 3) The issues that remain open whenever a city has to be designed and the way in which it will be lived by humans. These issues are not the most important ones in general, but they are indeed crucial for a design intervention.

\section{Three ways to design behaviours \\ Nudges}

In a recent book, Thaler and Sunstein explore the concept of nudge as a support for policy-making (Thaler \& Sunstein 2009). Their nudge concept is a critique of current policy-making processes, which, often (implicitly), assume traditional decision-making models, based on the "homo economicus" view. According to this view, humans are able to optimise their utility by weighting benefits and costs. Thaler and Sunstein argue that policy making processes should instead consider the more recent developments of decision-making theories such as, for instance, the impact of emotions on decision making (Damasio 1995), or the studies by Kahneman 
and Tversky on heuristics and biases (Kahneman 2011). Such a framework would advise policy makers to try and influence (i.e., to nudge) citizens toward desired behaviours, rather than by enforcing them, or renouncing to exert any form of influence.

Examples of decision making heuristics and biases include the classical Kahneman's ones, like:

- Anchoring: relying too heavily on the first piece of information offered (the "anchor") when making decisions, by adjusting our choices by implicit reference to this anchor.

- Availability: predicting the probability of an event based on how easily an example can be brought to mind.

- Representativeness: where people judge the probability of an event by how much it represents available data.

To which the authors add:

- Status quo: continuing a course of action because of tradition.

- Herd mentality: being heavily influenced by the actions of others, e.g. peers' pressure.

All these biases stem from the idea that humans may exhibit two different types of behaviour, shaped by the intervention of two different control systems. System 1 is fast, instinctive and emotional. It understands the situations at first sight, by gut feelings, by reacting instinctively without thinking. System 2 is slower, deliberative, and logical. It is called upon when we are involved in "decisions", we stop and think, we evaluate the different options and we eventually make up our mind. Our behaviour is shaped by both of them, with System 1 providing "answers" in most situations, while System 2 intervenes only in some specific instances, or when we decide to cross-check what System 1 is telling us. Our policies are too often designed for System 2, while choice engineering could also exploit the characteristics of System 1.

Sunstein and Thaler advocate that policy-making should balance libertarianism and paternalism. People should be free to do what they like (libertarianism), but policy makers can well try and influence people's behaviour in order to make their lives longer, healthier, and better. In other words, policy makers should design rules, settings, and cities in our case, in order to nudge people in a desired direction, leaving them free to act differently if they want to do so. An example would be placing healthy foods in a school cafeteria at eye level, while putting less healthy food in less-at-hand places. Individuals can still choose what to eat, but the food is arranged as to reinforce the healthy choice and decrease the consumption of junk food (Thaler \& Sunstein 2009).

When it comes to designing the future of a city, the concept of nudges is appealing. Designers can intervene to direct people's behaviour in one direction, while leaving them free to choose. This could apply to aspects as different as regulating the speed of cars in a specific road (a nudge would be the display of recorded speeds, without any ticket attached to it), or to more general ones like convincing commuters to use public transportation or carpool. Nudges seem to be particularly relevant as they rely on soft recommendations, which can be easily introduced in an urban setting without dramatically changing its structure (e.g. building roundabouts and installing speed cameras to regulate speed).

A nudge can take the form of an artefact or a tool, but effective nudges can also be immaterial, for instance, when a set of choices is presented in a certain order to exploit the anchoring effect. Choice architecture can exploit all the tools of the designers' trade, from physical artefacts to designing interaction modalities. The book, for instance, mentions some of the well known examples of affordances developed by Don Norman (Norman 1988).

\section{Persuasive design}

The idea that design can gently nudge the user in one direction, or another, has already been around for a while in the Interaction Design community (Fogg 2002). The basic concept behind persuasive technologies is that technologies are not neutral. They can encourage users in doing what we want them to do, whether this is increasing the amount of money spent on a web site, or diminishing energy consumption, or reducing calories intake.

Fogg proposes three categories of persuasive technologies: tools, media, or social actors (Fogg 1998). First, technologies can be tools, i.e., they can increase our ability to carry out a task. For instance, a sign helps us navigating an unknown town. Second, they can convey a narrative, a story, to create persuasive experiences. In such a function, they act as media. Third, technologies can also function as social actors, by mimicking some social cues and triggering related behaviours. For example, computers can be more attractive (e.g., a well designed interface), they can praise and reinforce desired behaviours (e.g., to do applications that congratulate when one finishes the tasks of the day), they can enhance some traits that make the computers' behaviour similar to that of the user (e.g., language and jargon).

In its most general and simple formulation, the design of persuasive technologies follows a three steps' method (Fogg 2009b): 
- Get specific: clarify which behaviour you want to obtain, by translating your goals and targets into users' behaviours.

- Make it easy: support the behaviour and make it easier to carry out.

- Trigger the behaviour: identify and/or design triggers for the target behaviours.

According to Fogg, a behaviour takes place because people are motivated to act and because it does not cost too much to them, because it is simple, or they already possess the skills to carry it out (Fogg 2009a) Figure 1. Persuasive technologies can then increase the chances of people to behave in a specific manner by increasing the motivation (rhetorical function, typical by narratives or social cues), or by making the task easier (the tool category). Motivation may also rely on sanctions, be monetary or social ones, while simplicity can be paired with use of resources, physical or mental effort, novelty of the task. Once the designer has acted on these two aspects, $\mathrm{s}$ /he has to design a trigger, to tell the user when the time is to perform a behaviour. Fogg mentions three trigger types:

- Spark: this trigger leverages on motivational aspects and tries to activate a behaviour by highlighting one the motivational aspects described above.

- Facilitator: this type of trigger tells the user that the specific behaviour is easy to do. It is an appropriate trigger in those cases where the users lack ability but have high motivation.

- Signal: this trigger is a reminder. It does not motivate or tell that the task is easy, because users have both the ability and the motivation to perform it.

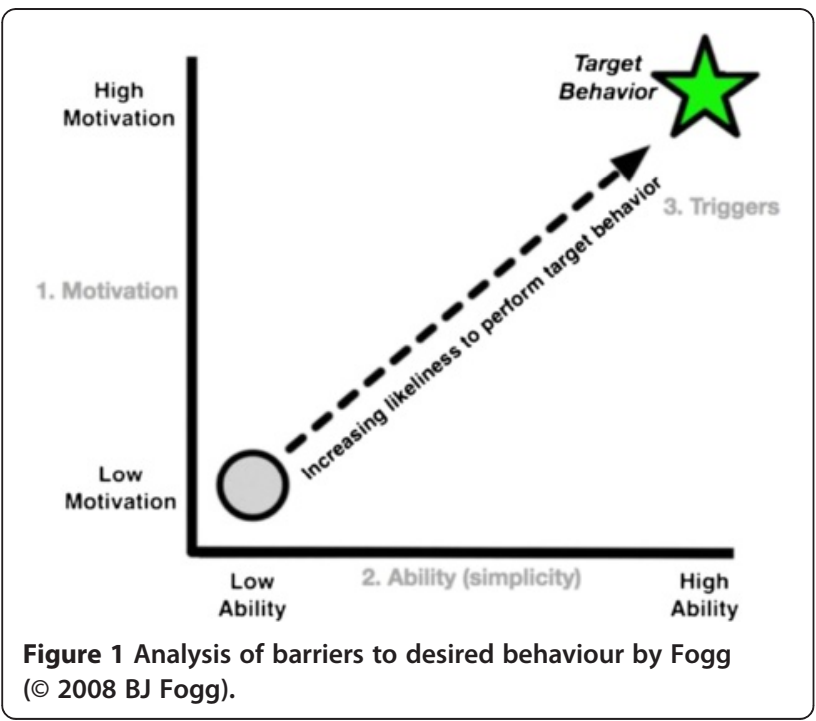

The joint design of these three aspects increases the chances of users performing a desired behaviour.

What is remarkable about the persuasive technology approach is that it does not imply giving the user lots of information in order to convince her/him. It is about designing tasks and support elements in order to increase the chances of seeing desired users' behaviours. For instance, green behaviours can be activated by making simple for users to save energy, by increasing their motivation to do so (for instance displaying the money saved), by triggering their actions in specific circumstances. As a practical example, the NEST thermostat shows all the three features. It helps the user set a conservative heating schedule by monitoring one's habits and adapting the daily schedule to them. At the end of the month, it can show how much energy was used and how much it was saved thanks to the NEST's support. In specific cases (e.g., warm winter days), it even prompts the user to reduce the target temperature to save energy Figure 2.

Similar technologies are nowadays available in cars, to monitor the drivers' behaviour and offer them customised driving advices (e.g. best routes, inefficient driving styles) to reduce fuel consumption.

\section{Design thinking}

The last approach we would like to cover is named Design Thinking, brought forward by design firms like IDEO and by university courses like the D-School at Stanford. The hallmark of Design Thinking is driving innovation processes with human-centred methods and principles (Brown \& Kātz 2009). It sees innovation opportunities as chances to strike a better balance between what is technologically feasible, what is desirable from the user's point of view, what is economically viable. Most of all, it sees every project as a possibility to make an impact on reality, to design the world.

This approach advocates for design to play a different role in the innovation process than it has traditionally done. Typically, designers were called in at a very late stage in the process, to wrap the idea and make it more

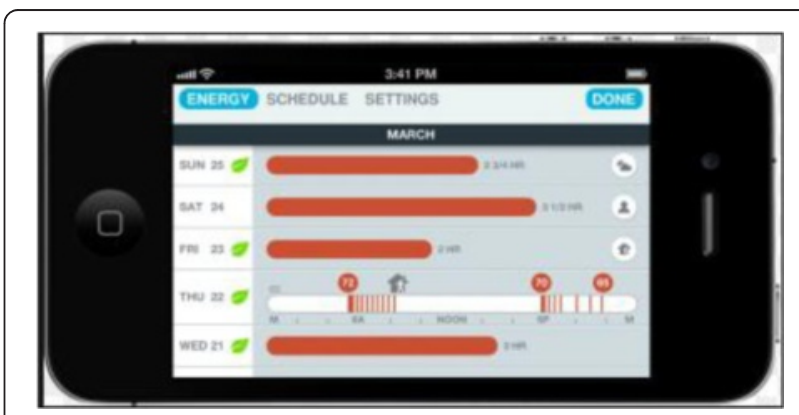

Figure 2 The NEST mobile interface. 
aesthetically attractive, appealing. Design thinking requires a multidisciplinary approach, as the problems, it aims to address to, are typically very broad in scope and complex. Design thinking sees design as taking a strategic role, by creating ideas that better meet the users' needs and desires. Such a shift is even more compelling in a service-driven market, where designers do not "only" wrap products, but have a distinctive competence to mix together a variety of material products and immaterial processes to deliver a service with increased added value.

The process for design thinking moves across three moments or phases, with multiple iterations. There is the Inspiration moment, where the team analyses the current situation for problems and opportunities, existing constraints, to steer the search of solutions (be them either technologies or services). The second moment is about Ideation. This is when ideas are generated, developed and tested by means of prototypes. This phase involves a lot of trials and errors, by pursuing a solution, exposing it to users in a prototypical form, and realising it is still not the right one. When a clear vision for a solution is achieved, the project team moves to the Implementation phase, where the solution has to be engineered and deployed to the market. As stated above, the process is highly iterative, and these three moments are more areas, spaces, where different activities go unfold, rather than a sequential process. The innovation process is about constant refinements, craftsmanship (Kolko 2011), daily practice and improvement, form following failure (Petrovsky 1992).

At its foundation, design thinking exploits many wellknown techniques of user-centred design (Norman \& Draper 1986). Each project should build on the sound understanding of what the users need and desire, by observing them, interviewing them, interacting with them. The major difference is that the design thinking approach positions its contribution mostly at the strategic level, thus shifting the emphasis away from techniques towards steering the whole project. User-centred design can be applied by an user-centred design expert as an add-on to an otherwise traditional engineering project, while design thinking requires involving a whole team, all of them working with the design perspective. Another difference lies in the historical contingencies. Usercentred design was mostly about designing successful products, while design thinking has to address service and experience design.

\section{The city as a multi-layered system}

The approaches above summarized address the same issue, i.e., designing and intervening on the world. They do it at different levels (very general and strategic, or detailed for a specific tool), with different scopes. None of them is THE SOLUTION for the design of a city. They all contain good elements, but some issues still remain. A city is complex: There are too many users, city is used (i.e., lived) in too many ways.

Indeed, a city needs to be analysed as a superimposition of different layers, represented by its physical elements and by the various ways in which the city is being used. These layers can be conceived in analogy to those typical of a building. In his book "How Buildings Learn" (Brand 1995), Steward Brand identifies six different timeframes that should be analysed to understand how a building changes during its lifetime.

1) The site. The geographical location, where the building is positioned in space and the surrounding context, never changes; it stays the same, while the context (including the web of social interactions that take place therein) may not change, or may be subjected to very slow transformations.

2) The building structure. The structural elements are hard and costly to modify, so they tend to remain stable over long time periods. This typically means from 30 to 300 years.

3) Then, there is the external surface, the "skin". Its lifespan is in the order of 20 years, as it gets renovated to update the style, for routine maintenance, or to apply new technologies, like in these days it is done to improve the thermal isolation of a building.

4) The internal services are the next layer. Examples include the piping systems, the air conditioning, the electrical system, or moving parts like the lifts. When these services are too old and too costly to upgrade (because they are too integrated into the building structure, it often happens that the whole building is demolished and re-built. Otherwise their lifespan is in the order of 7 to 15 years.

5) The space plan includes the internal layout, walls, ceilings, floors, and doors. The fashion impact is crucial here. Too much attention to trends and current fashions may result in changes as often as every 3 years. Less "dynamic" houses may be renovated every 30 years.

6) The last layer is "stuff": furniture, electrical appliances, lighting and lamps. Their lifespan is typically short and subject to changes, sometimes even less than one year.

Understanding these aspects is crucial for Steward Brand to better design and plan any intervention on the building itself. They help putting in the right perspective each decision, appreciating its impact and duration. The various layers need to have an internal consistency. It is also a matter of coherency among the different aspects of a project. The layers need to be thought of as 
interdependent. The interior design has to be coherent with the site, as the furniture with the infrastructure. It does not have to conform to, but the architect has to be aware of all the six levels while designing. S/he has to be aware of the different speeds of change especially, as this may make the layers change without any coherency and coordination, driven by different motivations.

We may apply the idea of multi-layered design to the city. Contrary to a building, the city layers are harder to match to a specific physical element. The time dimension is instead crucial here, because some of these layers describe the way the city is being used.

We have again the "site" layer, in analogy to the building site. A city is founded on a specific site, which means weather, access to natural resources, proximity to other cities. The site has a clear impact on the future of a city, affecting the possible developments, facilitating some expansion lines against others. This dynamic is nicely represented in city maps where the year of construction of the various building is colour coded, showing how the site layer expanded with time and along which directions.

This layer refers to long-term dynamics, like the growth of new neighbourhoods, or the re-purposing of existing ones.

The "structure" layer is also relevant, as a city is based on a certain number of infrastructures: the most noticeable ones being the road network and the spatial distribution of different neighbourhoods. At this layer we have the first remarkable difference between the building layers and the city ones. The city structure is physical but it has to be based on its social use: the road network coordinates the individual movements, it does not only connects two points in space. The road network needs to consider technological issues (how to go from point A to point B), but it also has to account for how many persons want to go from point $\mathrm{A}$ to point $\mathrm{B}$, when they want to travel, with which means of transportation, and, eventually, whether these same persons would rather reach point $C$, instead of $B$. A road network defines the way in which you could travel, but the roads taken by the various travellers also matter, to the point where they could open up new roads. The city structures need to bring into coherency their technical existence with the social behaviour of their users. Other examples include all the structures for moving people or freight, like railroads, or underground systems. The image below shows a simulation of the mobility in the territory surrounding the area that will host the Milan EXPO2015 fair, performed by Systematica S.p.A. Figure 3.

The "skin" layer seems less important, for sure less important than the "services" layer. At this layer we have all the different infrastructures that make the city function. Examples include the aqueduct and the sewage systems, the network of energy (e.g.. electricity) distribution, as well as communication networks, like the telephone, or the Internet (if different than the telephone) ones (Ascher 2005) Figure 4.

This layer encompasses real physical infrastructures, but also networks that weave together a set of relationships, like the communication infrastructures. The latter may be real infrastructures like the telephone network, but also purely relational ones, like the exchange of paper mail, or the goods distribution services. Just like the structures, services need to bring into coherency their existence with their social use, and even more, because services are often the driving force behind the social use of the other structures and services, as it is often the case of relational services which need to rely on the structures to accomplish their goals, like the post service uses the roads to deliver mails.

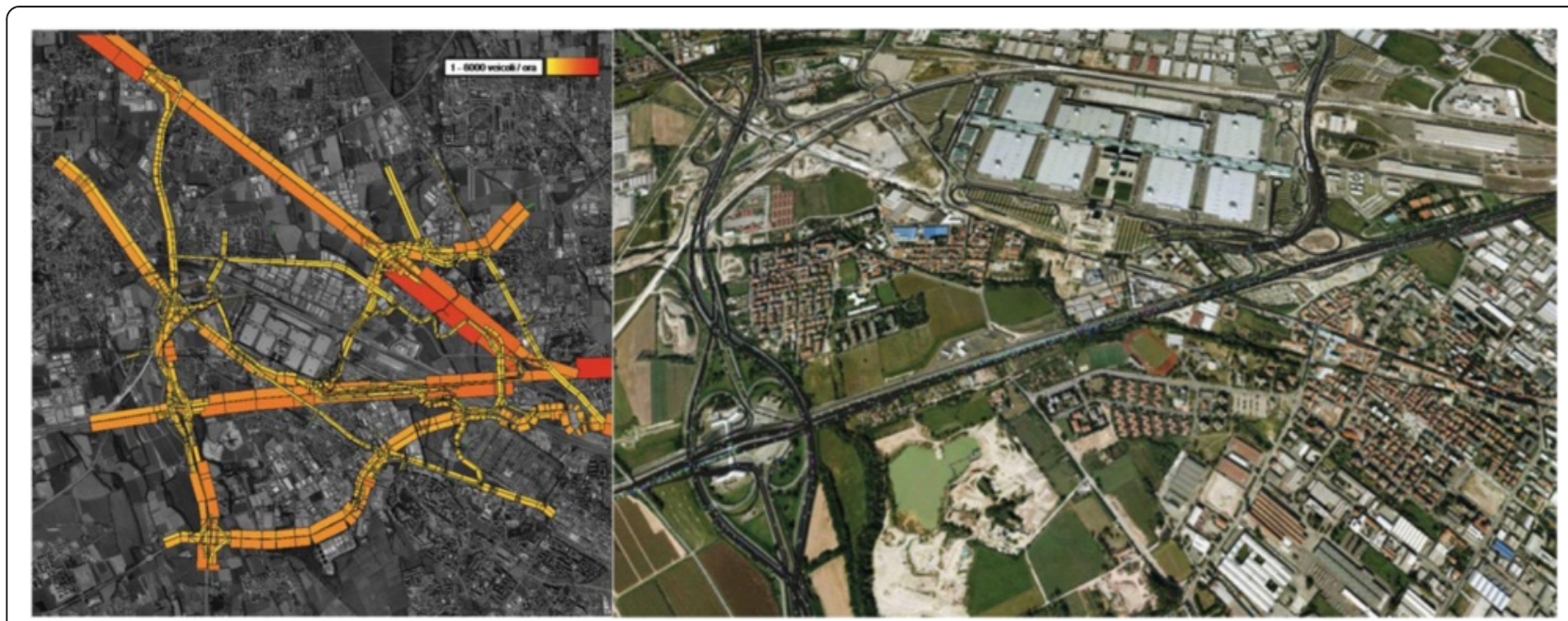

Figure 3 A simulation of the mobility for Milan EXPO2015 fair, performed by Systematica. 


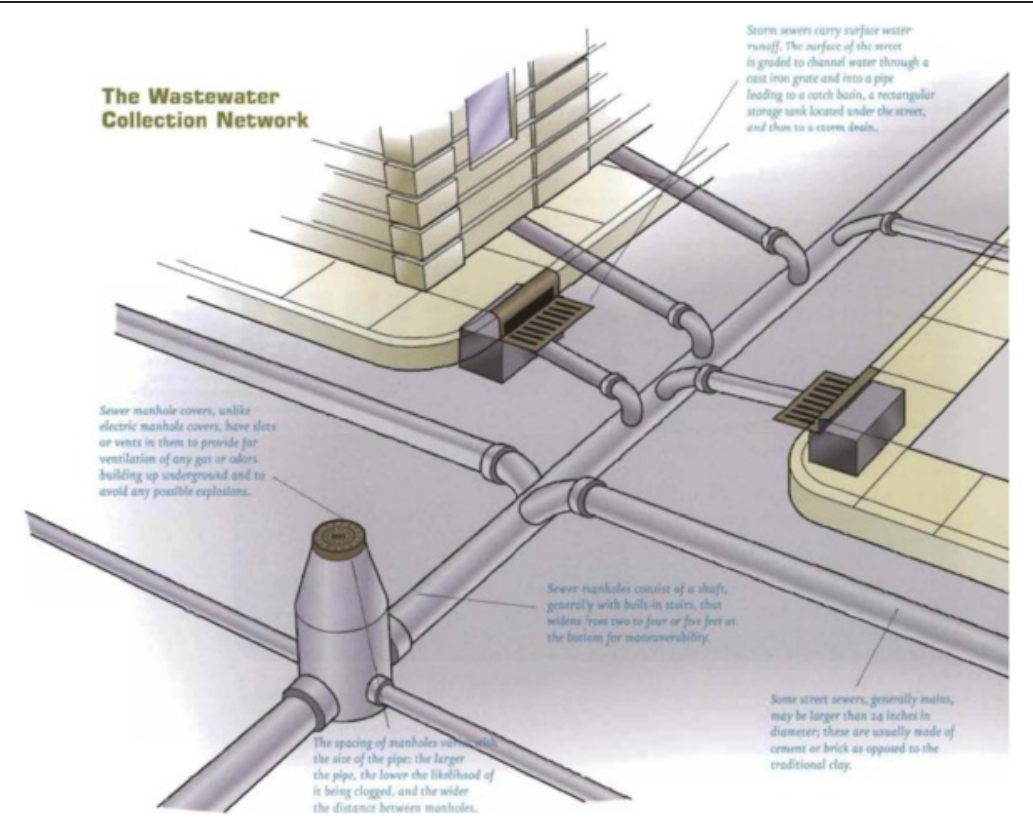

Figure 4 Image from (Ascher, 2005).

The "space plan" and "stuff" layers are tightly merged in a city. The layout of squares and public areas changes by changing space plan elements like sidewalks, roundabouts, light posts, trees, and so on, but also by intervening on stuff: chairs and benches, fences, tables, etc..

Many of the examples discussed above weave together the space and the time dimensions. A city has multiple spatial layers, and in addition many of them change in time and fluctuate seasonally. Figure 5 and Figure 6 display some of these changes in time, while the picture of traffic flows around Milan would be very different if analysed across seasons and days. Indeed, at variance with a building, cities undergo to drastic changes due to fluctuations in time, seasonal dynamics, and long-term trends. Some cities do not look the same in two different seasons, or if we compare the weekends with the weekdays. These changes affect all the city layers, but may be hard to notice and to identify. The time dynamics are important also because they may capture differences in the use of the city. Looking from the time dimension, the physical part of the layers stays the same (at least to some extent), what really changes and drives the changes is their social use.

Another important difference lies in the inertia of the layers, which is maximum for the site, structure, and services. These layers are hard to redesign once in place. They can be more easily built than destroyed. They can be modified, but not totally redesigned. The recent reuse of industrial areas, turned into hubs for the creative class, or for the night-life, is a good example, where repurposing does not mean total redesign. The site and the infrastructure layers stay there, services are partially changed, the space plan and stuff layers are repurposed.

There is a straightforward economic reason for this. The investments on infrastructures are high and they deploy technologies which cannot be easily changed. For instance, pneumatic mail was still in use in Paris till 1984, long after it had become technologically obsolete (it was abandoned in 1953 in New York).

\section{Multiplicity of users}

Interaction design can offer a sound and robust method to address the complexity of a city. It can help analysing the situation, identifying opportunities and problems, putting solutions in place. This method is crucially dependent on the principle that solutions should be designed around the target users. The identification of which opens some further questions in the case of a city.

A major aspect to discuss about a city is its multiplicity of users. When it comes to design intervention, all the approaches discussed in the first section start from the idea (more or less explicitly) that we must know our target users before we can deploy effective interventions. In a city, this is more easily said than done. A city has multiple users, and before we can start to analyse them, we would need to identify them. Who are the users of a city? Are they inhabitants, or recent immigrant, or tourists, or one-day businessmen?

These may seem obvious questions, but they do undermine the core of most design methods. User-centred design is at the basis of the approaches of persuasive technologies and design thinking; it is not explicitly addressed 


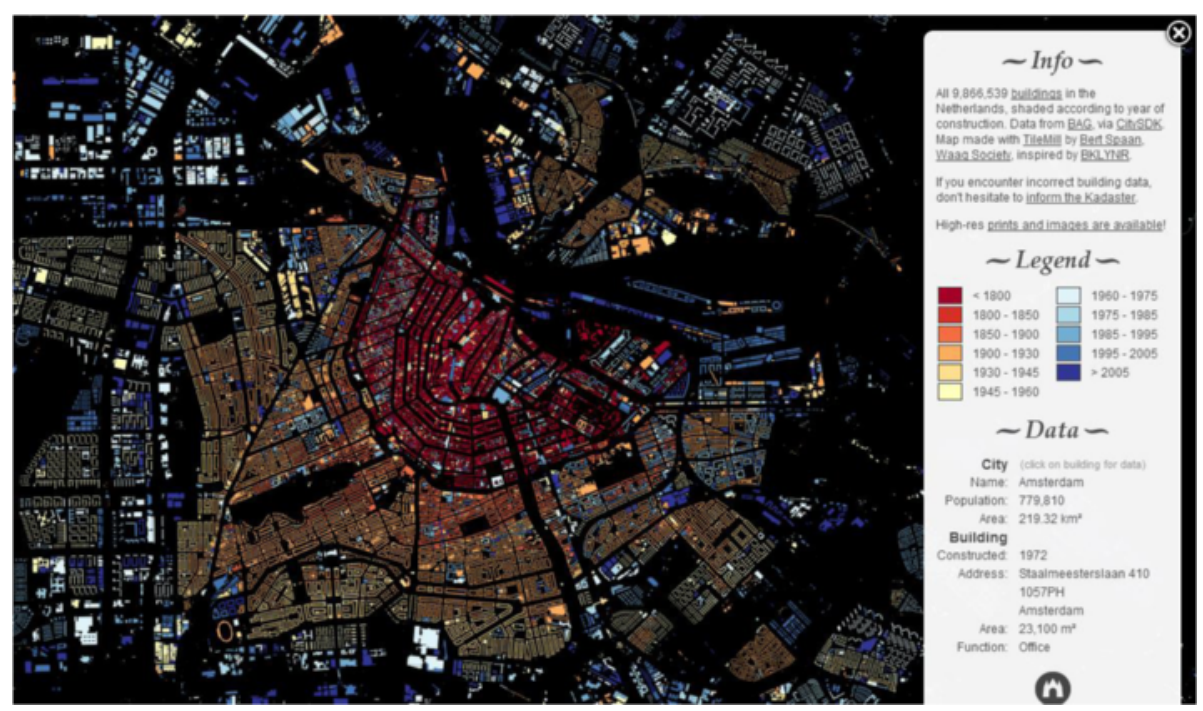

Figure 5 A map of Amsterdam with building year of construction (map produced by Bert Spaan, Waag Society).

in the discussion on nudges, but an effective nudge requires a good understanding of how humans behave.

User-centred approaches maintain that successful innovations are better driven by understanding of what users want. Users have to be observed and interviewed, their long-term needs and goals should to be identified. These insights are often modelled in user requirements, or in design personas (Nielsen 2013). Design personas summarise the results of user research and represent potential user types.

The advantages of user-centred design, and of tools like personas, are to keep the designers focused on specific problems and not on general ones, to help in deciding which features should be prioritised and which are simply "nice to have", or even useless. The end goal is to avoid technology-driven design process, in order to create technologies that can actually improve the life of their users, addressing actual needs. Non-users are also important, to clearly define whom we are not designing for.

In the case of a city, designers are confronted with a multiplicity of users. If there are too many users, it is very hard to design for each one of them. How do we understand their needs, goals, resources, to decide who are our primary or secondary users, who is out of our target requires a political choice. The situation is even made more complex by the increased mobility of

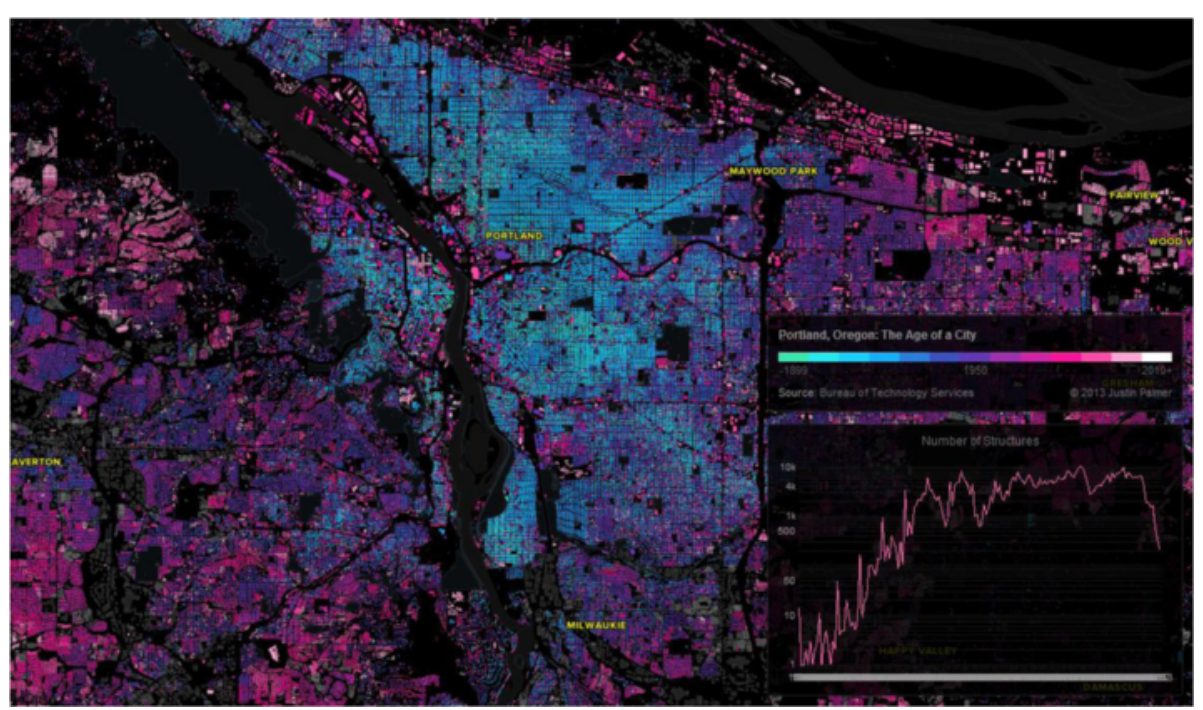

Figure 6 A map of Portland with building year of construction (map produced by Bert Spaan, Waag Society). 
citizens, for instance, influenced by direct low cost connections with distant cities, or waves of immigration.

The recent case of Taksim square in Istanbul illustrates this point. On a normal day, Taksim Square is a chaotic mess, with buses, taxi horns, shops, and so on. And crowds; many different crowds. Taksim is fluid, irregular, open and unpredictable, reflecting the area's historic identity. It was where poor European immigrants settled during the 19th century. It was a haven to gays and lesbians, a locus of nightclubs, foreign movie palaces and French-style covered arcades in the 1980s. Gravestones from an Armenian cemetery at Taksim demolished in 1939 were used to construct stairs at Gezi Park. Turkey's prime minister determined to clean it up and to make it into an orderly pedestrian zone, with a new mall, mosque and tunnels to hide the traffic underground. It was a political choice, stating who the primary users are, selecting some among others. In the case of Taksim, it was a choice that reduces the complexity of users: It "cleans" the chaotic public space in favour of selected uses. This is why such a choice stirred so vibrant protests. The big pedestrian plaza will make the square more ordered. But it will do more. It will select the users.

Such a level of complexity may turn out in ill-focused interventions, but there are two ways to deal with it. On the one hand, the multiplicity of users in a city is an ideal playground for big data approaches, to cluster users around patterns of behaviours and goals. This field of study is blooming in these years, thanks to the increased use of low cost sensors and geo-tracking devices. Data driven methods and techniques can be extremely useful to monitor and study the dynamics of users appropriation. Indeed, most innovation processes today start with the technology being directly deployed on the market or in the workplace (Scott 2009). The role of interaction design is then to steer the future in one direction, not to predict it. Design is about formulating "hypotheses or beliefs about the relationship between technology and cognition/ collaboration", making them tangible in whatever form, and then monitoring and steering the way the real world adapts to these hypotheses (Woods \& Dekker 2000). This would result in the following typical steps:

1) Deploy innovation.

2) Users analysis (starting from their actual behaviour): (i) identify clusters of users and highly individual behaviours, (ii) extensive and intensive users study.

3) Redesign.

User-centred evaluation is done in the wild, by monitoring actual technology use. Individuals are monitored in the actual use of technology, not during users studies that will only later feed the design process. In this case, interaction design methods are still applicable, but should be complemented by: (i) statistical approaches to cluster users and single out relevant outliers, (ii) ethnographical approaches and other observational methods. Real behaviours are to be monitored, to identify the relevant ones to steer the design progress. No matter how extensive the user analysis, the users' adaptations to new technology will always bring some surprises, so rather than relying on a general model to predict these adaptations, constant monitoring of real world dynamics should be in place to fine tune expectations.

A second design approach aims to initiate disruptive innovation processes. Interaction designers sometimes rely on "extreme users" to give away with well-established mind-sets and solutions. The individuals are treated like catalyst of innovations, and the more idiosyncratic the use of a technology is, the more interesting for the design team (Pozzi \& Bagnara 2013). Individuals are treated as sources of inspiration, triggering "deep and thick" studies on each person's daily routine. The typical steps may be the following ones:

1) Identify idiosyncratic uses of technology.

2) Design using individual behaviours as inspiration.

3) Evaluation with users if research led, or directly deploy if design led.

4) Redesign.

In this case, individuals are best valued when they steer away from the status quo, or they diverge from "standard" uses, or they may be exploited as catalysts of innovation. Interaction designers have the methods to involve users in collaborative design sessions (e.g. providing means for users to design their own solutions), to foster the adoption process by other users (e.g. supporting the sharing of solutions with other users, favouring the spontaneous aggregation of users around key catalysts).

\section{Breakdowns as moments of selective visibility}

There is another approach. The complexity of a city may hide some relevant users and layers, leading the designer to focus on the wrong ones. Users in a city may become invisible, in the sense that their use affect the city layers, but they may leave no visible trace. Layers themselves may also become transparent, invisible, in the sense that they are taken for granted. They are used, and then fade in the background. Visibility/invisibility may happen to a different degree. Some layers are easy to see, others are not. The same happens for users. This selective invisibility is key to understand a city, as the design intervention may concentrate too much on what is there, overlooking the importance of what is hidden.

This is a known phenomenon in the human-machine interaction studies. Tools are conceived by users in two different modalities: 'ready-to-hand' and 'present-at-hand' 
(Chalmers 2004). Ready-to-hand tools are transparent when we use them, "literally visible, effectively invisible" (Weiser 1994). They are dovetailed with our cognition. On the other side, a tool like a hammer may become "present-at-hand", when it breaks and loses its usefulness, or, at the first encounter, when we do not know how to interact with it.

These two modalities may be conceived as separate, but reality is that we continuously move between the two poles in our daily activity. Tools become ready-tohand usually after some usage, they may revert to present-at-hand in case of breakdowns in the activity and, to a certain extent, the more we shift between the two modes, the more we are able to effectively master a tool and make it fully transparent in our activity. All the city layers we discussed above share this dynamic, even if they are far more complex than a hammer: they are invisible while we use them to achieve something, they become visible only when a problem emerges. In these moments, their users usually become visible as well.

Winograd and Flores (1986) have proposed to consider these moments of visibility as opportunities to achieve a better understanding of the way a tool really works. Firstly, a breakdown interrupts the user's flow of action, and diverts her/his attention to the tool itself. It is the best moment to engage in reflective thinking. Secondly, the breakdown highlights some of the tool working mechanisms, thus supporting a better understanding of why the things work as they do. In this interruption, there is the opportunity to improve the tool and the way we interact with it.

The concept of breakdown is relevant for our present discussion for two reasons. First, breakdowns may happen in the normal functioning of a city and increase the visibility of city layers and users, similarly to what proposed by Winograd and Flores. Second, the notion of breakdown as "interruptions of the action flow" may be extended in a city to include out of the ordinary events, like fairs, social events, strikes, and so on, and not only actual breakdowns.

This is well captured by the work of the Senseable city group (senseable.mit.edu). This research lab explores the way cities function by analysing the vast quantities of data produced by digital technologies. For instance, they analysed the patterns of text messages during presidential elections, social events and parades, sport events, and so on. They use these data to bring to the surface the interaction between people and the city setting, to uncover some of the hidden patterns.

The project Signature of Humanity (Robinson \& Cruz 2013) analyses voice, sms and data traffic in major cities from various continents, to find patterns and differences among nations, to see how these patterns are affected by special events, and if they are differentiated in the different city areas. The results are still preliminary, indicating that same-country cities are more alike, and that all major cities show a partitioning of spatial areas with specific patterns.

The project Real-time Rome (Calabrese et al. 2011) addresses instead the following research questions (among others):

- What are the patterns of use in Rome?

- Where is traffic moving?

- Where are tourists congregating?

- What does Rome look like during special events?

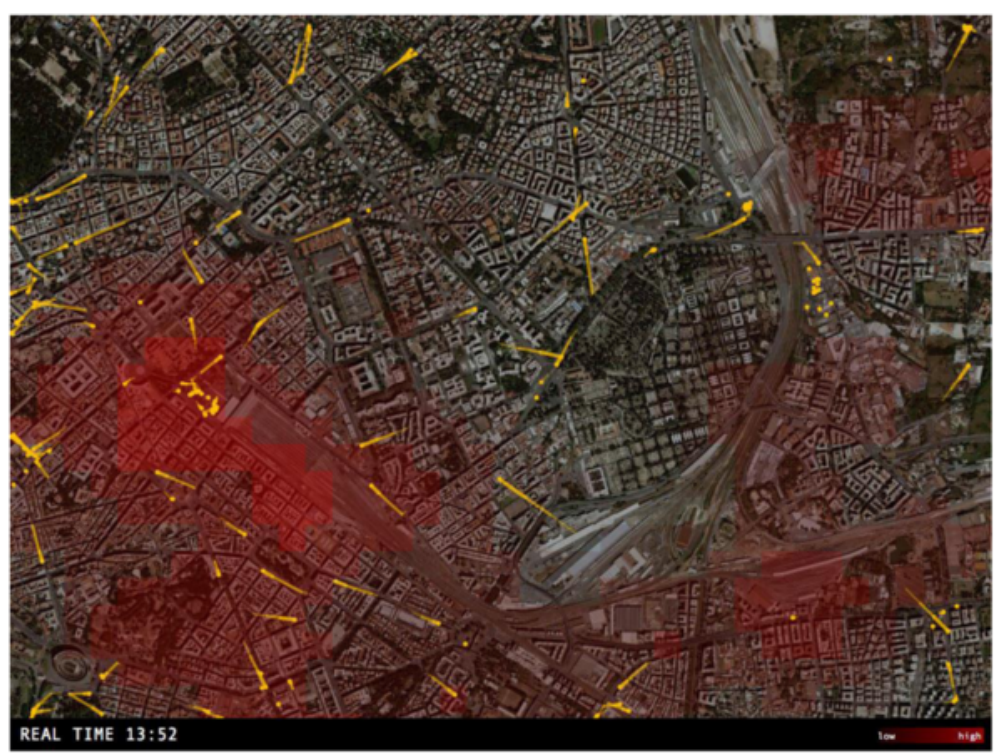

Figure 7 An image from the Real-time Rome project. 
In this project, data coming from the use of digital technologies are used to visualise parts of the hidden city layers and the behaviour of the different users. The comparison between the normal patterns and the ones engendered by special events is also exploited Figure 7.

The extension of the breakdown concept to out-of-theordinary moments gives more opportunity to analyse a city, its working mechanisms and layers. However, there is still one issue remaining. Human-tool breakdowns are learning opportunities, as the tool inner working processes are exposed and presented to the user's understanding. The same is not true for a city breakdowns, like it is not true for most of the modern infrastructures, as discussed in a previous work (Bagnara \& Pozzi 2013). City breakdowns do attract the user's attention, but they seldom enhance the understanding of the way the city works. A city is so complex that breakdowns only selectively highlight some elements (the non-functioning ones). We may perceive only a limited part of the problem, or we may even see only the end results of some distant event, as is the ripple effect through space and time of traffic problems. The whole complexity cannot emerge and the elements that become visible may not be the best ones to improve our understanding.

\section{Conclusion}

In the above discussion, there is a tension between the applied nature of interaction design tools and methods on one side, and the complexity of a city on the other. In interaction design, context is everything. The intervention has to be thought by considering the details of each specific situation, by possibly tailoring the solutions on each user. Such an approach may remain valid when the intervention happens in a city, but it requires some dedicated thinking. The complexity of a city, the number of aspects to be considered, the multiplicity of potential users may simply be too much to handle for a traditional interaction design approach. However, it our belief that interaction design approaches, methods and tools would be useful for the design of a city.

This contribution outlines few approaches, reviews some available methods and analysis categories to identify users and to derive design insights from them. Eventually, we proposed the concept of breakdown as a tool to grasp hidden dynamics and to support the identification of the right target users.

For the approaches, we proposed to span from local solutions on material artefacts (with persuasive technologies), to strategic interventions finding "solutions" at various levels (design thinking), to gentle pushes (nudges) to human behaviour, by shaping policies to increase citizens' wellbeing.

For the categories of analysis, the proposal is to use city layers as described above. City layers are defined by the interplay of their physical structure with the way they are used, so a focus on one layer brings the question of which users (among the multiple ones) to select. Two possible strategies were outlined, on one side a design intervention with data driven progressive adjustments, on the other hand using individuals as innovation catalysts.

The complexity of a city is due to the interplay of material and immaterial, but also to the temporal interdependencies among the layers. One layer is affected by changes at another layer, both in a top-down and in a bottom-up directions. Changes to the site may affect the structure, changes to the services may trigger upward changes to the infrastructure or downward to the space plan. Each layer also exhibits its specific time dimension. The concept of breakdown can be applied to have a disciplined method of identifying which layers to study, to follow the dynamics between the various layers, and also to identify the target users.

Interaction design is probably not THE solution for designing cities worth to living in, but surely it can help in such an intriguing and challenging aim.

\section{Competing interests}

The authors declare that they have no competing interests.

\section{Authors' contribution}

The authors have equally contributed to all phases of this work. Both authors read and approved the final manuscript.

\section{Author details}

1University of San Marino-IUAV, San Marino Città, San Marino \& Deep Blue Consulting and Research, Rome, Italy. ${ }^{2}$ University of San Marino-IUAV, San Marino Città, San Marino \& BSD, Rome, Italy.

Received: 9 December 2014 Accepted: 10 December 2014 Published online: 26 February 2015

\section{References}

Ascher K (2005) The Works. Anatomy of a City. Penguin Books, London, UK Bagnara S, Pozzi S (2013) L'infrastruttura Invisibile: la Rete Degli Aeroporti e del Trasporto Aereo. In: Infrastrutture Tecnologiche e Creazione del Consenso. Rubbettino Editore, Soveria Mannelli, Italy, pp 229-250

Brand S (1995) How Buildings Learn: What Happens After They're Built. Penguin Group, New York, New York, USA

Brown T, Kātz B (2009) Change by Design: How Design Thinking Transforms Organizations and Inspires Innovation. Harper Business, New York, New York, USA

Calabrese F, Ratti C, Colonna M, Lovisolo P, Parata D (2011) Rome. Real-time urban monitoring using cell phones: a case study. IEEE trans Intell Transp Syst 12(1):141-151. http://ieeexplore.iee.org/xpl/articleDetails.jsp? arnumber $=5594641$

Chalmers, M. (2004). A historical view of context. Computer Supported Cooperative Work (CSCW), 223-247. Retrieved from http://link.springer.com/ article/10.1007/s10606-004-2802-8

Damasio AR (1995) Descartes' Error: Emotion, Reason, and the Human Brain Harper Collins, New York, NY

Fogg, B. J. (1998). Persuasive computers: perspectives and research directions. In Proceedings of the SIGCHI conference on Human factors in computing systems (pp. 225-232). ACM Press/Addison-Wesley Publishing Co.

Fogg BJ (2002) Persuasive Technology: Using Computers to Change What We Think and Do. Morgan Kaufmann, Burlington, MA

Fogg, B. J. (2009a). A behavior model for persuasive design. In Proceedings of the 4th international Conference on Persuasive Technology (p. 40). ACM

Fogg, B. J. (2009b). Creating Persuasive Technologies: An Eight-Step Design Process. In Persuasive'09. Claremont, California, USA 
Kahneman D (2011) Thinking, Fast and Slow. Farrar, Straus and Giroux, New York, New York, USA

Kolko J (2011) Craftsmanship. Interactions 18(6):78-81

Nielsen, Lene (2014): Personas. In: Soegaard, Mads and Dam, Rikke Friis (eds.).

"The Encyclopedia of Human-Computer Interaction, 2nd Ed.". Aarhus,

Denmark: The Interaction Design Foundation. Available online at https:// www.interaction-design.org/encyclopedia/personas.html

Norman DA (1988) The Psychology of Everyday Things (p. xi, 257 p.). Basic Books, New York, NY

Norman DA, Draper SW (1986) User Centered System Design: new Perspectives on Human-Computer Interaction (pp. Xiii, 526). Lawrence Erlbaum Associates, Hillsdale, NJ

Petrovsky H (1992) The Evolution of Useful Things. A. Knopf, New York, New York, USA

Pozzi S, Bagnara S (2013) Individuation and diversity: the need for idiographic $\mathrm{HCl}$. Theor Issues ErgonTheoretical Issues in Ergonomics Science 14(1):1-21

Robinson, P., \& Cruz, P. (2013). Deciphering the Signature of Humanity. Ericcson Buisiness Report, 50-51. Ericsson.

Rogers Y, Sharp H, Preece J (2007) Interaction Design: Beyond Human Compute Interaction. John Wiley \& Sons, New York, NY

Scott KM (2009) Is usability obsolete? Interactions 16(3):6-11

Thaler, R. H., \& Sunstein, C. R. (2009). Nudge: Improving Decisions About Health, Wealth, and Happiness (Penguin Gr.). New York, New York, USA.

Weiser M (1994) The world is not a desktop. Interactions 1(1):7-8

Winograd T, Flores F (1986) Understanding Computers and Cognition: A New Foundation for Design. Addison Wesley Publishing Company, Reading, MA

Woods DD, Dekker S (2000) Anticipating the effects of technological change: a new era of dynamics for human factors. Theor Issues Ergon 1(3):272-282

\section{Submit your manuscript to a SpringerOpen ${ }^{\circ}$ journal and benefit from:}

- Convenient online submission

- Rigorous peer review

- Immediate publication on acceptance

- Open access: articles freely available online

- High visibility within the field

- Retaining the copyright to your article

Submit your next manuscript at $>$ springeropen.com 